\title{
NOTES
}

\section{Anionic Polymerization of Fluorine-Containing Vinyl Monomers XIII. Relative Polymerization Reactivity of ortho-, meta-, and para-Trifluoromethylstyrenes}

\author{
Tadashi Narita,* Tokio Hagiwara, and Hiroshi Hamana \\ Department of Environmental Engineering, Saitama Institute of Technology, \\ Okabe-machi, Osato-gun, Saitama 369-02, Japan
}

(Received April 11, 1990)

KEY WORDS Anionic Polymerization / Trifluoromethylstyrene / Initiation

Reaction /

Anionic polymerization of fluorine-containing vinyl monomers is of considerable interest since these monomers are expected to readily undergo polymerization with anionic initiators of relatively low basicity as the electron density of the vinyl groups is reduced by the high electron-withdrawing effect of fluoro- and fluoroalkyl-substituents. The anionic polymerizations of fluorinated acrylates and methacrylates have revealed that the polymers are produced with initiators of low reactivity such as organoaluminum compounds, and detailed study on initiation and propagation reactions has been reported. ${ }^{1}$

Though the same effect should appear in the polymerization of fluorinated styrene derivatives, only a few studies on the polymerization of these monomers with anionic initiators have been reported. ${ }^{2}$ The polymerization of $\alpha$ trifluoromethylstyrene has produced no polymer under radical and anionic polymerization conditions in spite of its high $e$ value $(Q=0.43$, $e=0.90) .^{3-5}$

As previously reported, the anionic polymerizations of ortho- and para-trifluoromethylstyrenes have, on the other hand, produced the corresponding homopolymers with initiators of relatively low activity which are unable to yield the polymer of non-fluorinated styrenes under the same reaction conditions. ${ }^{6}$ The reactivity of styrene derivatives is, therefore, strongly influenced by the strong electron-withdrawing trifluoromethyl group. Muramatsu et al. reported that the polymerization reactivity of trifluoromethyl-substituted phenylacetylenes was of the order of ortho->meta->paraisomer. ${ }^{7}$ This suggests the polymerizability is affected by the electronegativity of the $\mathrm{CF}_{3}$ group, which decreases with increasing distance between ethynyl group and $\mathrm{CF}_{3}$ group regardless of the steric hindrance of $\mathrm{CF}_{3}$.

In order to clarify the polymerization reactivity of ortho-, meta-, and para-trifluoromethylstyrenes the present report is concerned with anionic polymerization of meta-trifluoromethylstyrene ( $m$-TFMS) with several initiators. A comparison of polymerization reactivity of ortho-, meta-, and para-isomers of trifluoromethylstyrenes is also investigated based on yields of the polymers and examinations of initiation reaction.

\footnotetext{
* To whom all correspondence should be addressed.
} 


\section{EXPERIMENTAL}

\section{Materials}

$m$-Trifluoromethylstyrene was synthesized from $\mathrm{CH}_{3} \mathrm{MgI}$ and $m$-trifluoromethylbenzaldehyde in anhydrous ether, followed by dehydration with phosphorous pentoxide in anhydrous benzene; bp $51^{\circ} \mathrm{C} / 11 \mathrm{mmHg}$, total yield $37.2 \%{ }^{8}$ ortho and para Isomers were synthesized by the same method. ${ }^{6}$ The monomers were further purified by refluxing over $\mathrm{CaH}_{2}$ and distillation under reduced pressure, and stored under purified nitrogen. Toluene and tetrahydrofuran (THF) were refluxed over $\mathrm{CaH}_{2}$ and then distilled under nitrogen. 1,2Dimethoxyethane (DME) was refluxed with $\mathrm{CaH}_{2}$ and distilled under nitrogen. The distillate was further purified by refluxing with $\mathrm{Al}\left(\mathrm{C}_{2} \mathrm{H}_{5}\right)_{3}$ and distillation under nitrogen. Commercial $n-\mathrm{C}_{4} \mathrm{H}_{9} \mathrm{Li}$ and $n-\mathrm{C}_{4} \mathrm{H}_{9} \mathrm{MgBr}$ were used after determination of the concentrations of the active species by a double titration method $^{9}$ and alkalimetry, respectively. The disodium salt of $\alpha$-methylstyrene living oligomer was synthesized from sodium metal and $\alpha$-methylstyrene under nitrogen. $\mathrm{LiZnC}_{4} \mathrm{H}_{9}\left(\mathrm{C}_{2} \mathrm{H}_{5}\right)_{2}$ was synthesized from an equimolar reaction of $n-\mathrm{C}_{4} \mathrm{H}_{9} \mathrm{Li}$ and $\mathrm{Zn}\left(\mathrm{C}_{2} \mathrm{H}_{5}\right)_{2}$ under nitrogen. Potassium tertbutoxide was purified by sublimation in vacuo and stored under nitrogen. Commercial $\mathrm{Zn}\left(\mathrm{C}_{2} \mathrm{H}_{5}\right)_{2}$ and $\mathrm{Al}\left(\mathrm{C}_{2} \mathrm{H}_{5}\right)_{3}$ were distilled under reduced pressure and stored under nitrogen atmosphere. Diethyl(ethyl cyanoacetato)aluminum ( $\left.\mathrm{Et}_{2} \mathrm{AlECA}\right)$ was synthesized from equimolar reaction of $\mathrm{Al}\left(\mathrm{C}_{2} \mathrm{H}_{5}\right)_{3}$ and ethyl cyanoacetate according to the literature. ${ }^{10}$

\section{Polymerization}

$m$-TFMS $(6.7 \mathrm{mmol})$, initiator $(0.13 \mathrm{mmol})$ and solvent $(6 \mathrm{ml})$ were charged to a polymerization ampoule using a syringe under nitrogen atmosphere. The ampoule was sealed and kept at constant temperature. After an appropriate time, the polymer was isolated by reprecipitation with methanol and dried to constant weight.

\section{Initiation Reaction}

TFMS (10 mmol), Et ${ }_{2}$ AlECA ( $\left.1 \mathrm{mmol}\right)$, and DME $(10 \mathrm{ml})$ were added to a flask fitted with a three-way stopcock under nitrogen, and kept at $60^{\circ} \mathrm{C}$. After a given time, the reaction mixture was quenched by sampling a portion of the reaction mixture and adding it to acetic acid. The concentration of hydrolyzed product, ethyl cyanoacetate, was determined by vapor phase chromatography using $n$-tetradecane as the internal standard.

\section{Measurement}

Gel permeation chromatogram was measured with a TOSOH HLC-802A equipped with TSK gel G4000HLX-G3000HXLG2000HXL column series using THF as the eluent. Vapor phase chromatogram was recorded with a HEWLETT PACKARD 5890A equipped with DB-17 column.

\section{RESULTS AND DISCUSSION}

\section{Anionic Polymerization of m-TFMS}

In order to compare the reactivity of $m$-TFMS with that of $o$ - and $p$-isomers reported previously, ${ }^{6}$ the anionic polymerization of $m$-TFMS was examined with several initiators. The results are summarized in Table $I$. $n-\mathrm{C}_{4} \mathrm{H}_{9} \mathrm{Li}$, which is a well-known initiator for the living polymerization of styrene, gives relatively low yield in toluene, $n-\mathrm{C}_{4} \mathrm{H}_{9} \mathrm{Li}$ and $\alpha$-methylstyrene living oligomer dianion give polymers in appreciable yields in ethereal solvents. $n-\mathrm{C}_{4} \mathrm{H}_{9} \mathrm{MgBr}$, which is unable to initiate the anionic polymerization of styrene under the same reaction conditions, produces poly $(m$-TFMS $)$ though the yields are very low. $\mathrm{LiZnC}_{4} \mathrm{H}_{9}\left(\mathrm{C}_{2} \mathrm{H}_{5}\right)_{2}$, one of the 'ate' complexes which show high activity to the polymerization of fluoroalkyl acrylates and methacrylates, ${ }^{11}$ yields the polymer in DME. $\mathrm{Zn}\left(\mathrm{C}_{2} \mathrm{H}_{5}\right)_{2}$ and $\mathrm{Al}\left(\mathrm{C}_{2} \mathrm{H}_{5}\right)_{3}$ which are active initiators of 2,2,2-trifluoro-1-trifluoromethylethyl meth- 
Table I. Anionic polymerization of $m$-trifiuoromethylstyrene ${ }^{a}$

\begin{tabular}{|c|c|c|c|c|}
\hline \multirow{2}{*}{ Initiator } & \multirow{2}{*}{ Solvent } & \multirow{2}{*}{$\frac{\text { Temp. }}{{ }^{\circ} \mathrm{C}}$} & \multirow{2}{*}{$\frac{\text { Time }}{\text { day }}$} & \multirow{2}{*}{$\begin{array}{c}\text { Yield } \\
\%\end{array}$} \\
\hline & & & & \\
\hline \multirow[t]{4}{*}{$n-\mathrm{C}_{4} \mathrm{H}_{9} \mathrm{Li}$} & Toluene & 0 & 10 & 4.6 \\
\hline & & 60 & 10 & 5.0 \\
\hline & THE & 60 & 10 & 41.0 \\
\hline & DMF & 80 & 7 & 24.8 \\
\hline $\mathrm{Na}^{+}(\alpha-\mathrm{MeSt})_{n}^{2-} \mathrm{Na}^{+}$ & DME & 80 & 4 & 61.6 \\
\hline \multirow[t]{4}{*}{$n-\mathrm{C}_{4} \mathrm{H}_{9} \mathrm{MgBr}$} & Toluene & 0 & 7 & 1.0 \\
\hline & & 60 & 7 & 2.4 \\
\hline & THF & 60 & 7 & 2.0 \\
\hline & DME & 80 & 7 & 4.4 \\
\hline \multirow{4}{*}{$\mathrm{LiZnC}_{4} \mathrm{H}_{9}\left(\mathrm{C}_{2} \mathrm{H}_{5}\right)_{2}$} & Toluene & 0 & 10 & 0 \\
\hline & & 60 & 10 & 11.3 \\
\hline & THF & 60 & 10 & 5.1 \\
\hline & DME & 80 & 7 & 36.5 \\
\hline \multirow[t]{2}{*}{$t-\mathrm{C}_{4} \mathrm{H}_{9} \mathrm{OK}$} & Toluene & 60 & 7 & 2.4 \\
\hline & DME & 80 & 7 & 5.2 \\
\hline \multirow[t]{4}{*}{$\mathrm{Zn}\left(\mathrm{C}_{2} \mathrm{H}_{5}\right)_{2}$} & Toluene & 0 & 7 & 0 \\
\hline & & 60 & 10 & 2.1 \\
\hline & THF & 60 & 10 & 27.3 \\
\hline & DME & 80 & 7 & 24.1 \\
\hline \multirow{3}{*}{$\mathrm{Al}\left(\mathrm{C}_{2} \mathrm{H}_{5}\right)_{3}$} & Toluene & 60 & 12 & 0 \\
\hline & THF & 60 & 12 & 18.2 \\
\hline & DME & 80 & 12 & 9.4 \\
\hline
\end{tabular}

a Monomer, $6.7 \mathrm{mmol}$; initiator, $0.13 \mathrm{mmol}$; solvent, $6 \mathrm{ml}$.

acrylate ${ }^{1}$ and unable to initiate the polymerization of styrene and methyl methacrylate, ${ }^{12}$ produce polymers of $m$-TFMS with appreciable yields in THF and DME. The anionic polymerization of $m$-TFMS is found to yield the polymer with the initiation systems similar to those of ortho- and para-isomers reported previously. $^{6}$

Anionic Polymerization Reactivity of o-, $m$ - and p-TFMS

In order to clarify differences of the polymerization reactivity of $o-, m-$, and $p-$ TFMS, the $\alpha$-methylstyrene living oligomer dianion and $\mathrm{Et}_{2} \mathrm{AlECA}$ systems were investigated in more detail. The dependency of the polymer yield on polymerization time is shown in Figure 1. The yields of the polymers of these three monomers increase steadily with increas-

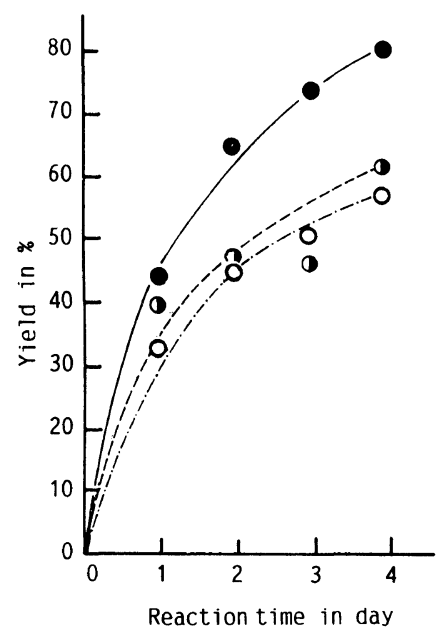

Figure 1. Time vs. polymer yield curves of anionic polymerization of ortho- $(\bigcirc)$, meta- (O), and para-TFMS (○) initiated with $\mathrm{Na}^{+}(\alpha-\mathrm{MeSt})_{n}^{2-} \mathrm{Na}^{+}$.

Table II. Polymerization of $o-, m-$, and $p$-TFMS with $\mathrm{Et}_{2} \mathrm{AlECA}$

\begin{tabular}{|c|c|c|c|c|}
\hline \multirow{2}{*}{ Run } & \multirow{2}{*}{ Monomer } & Temp. & Time & Yield \\
\hline & & ${ }^{\circ} \mathrm{C}$ & day & $\%$ \\
\hline 1 & $o$-TFMS & 40 & 7 & 12.1 \\
\hline 2 & $m$-TFMS & 40 & 7 & 8.6 \\
\hline 3 & $p$-TFMS & 40 & 7 & 22.0 \\
\hline
\end{tabular}

ing polymerization time and the increases of the polymer yields are of the order, para$>$ meta->ortho-TFMS, though very small difference is detected.

Prior to the investigation of initiation reaction, the polymerizations of the monomers with $\mathrm{Et}_{2} \mathrm{AlECA}$ were examined. The results are shown in Table II. $\mathrm{Et}_{2}$ AlECA is also fairly active for the anionic polymerization of these three monomers at $40^{\circ} \mathrm{C}$ in DME. GPC of poly $(p$-TFMS) obtained here is shown in Figure 2. The molecular weight distribution is unimodal and the molecular weight of the peak calibrated against monodisperse polystyrene standards is $1.4 \times 10^{5}$. ECA moiety was not detected at the terminal by measurement of ${ }^{1} \mathrm{H}$ NMR since the molecular weight of the 


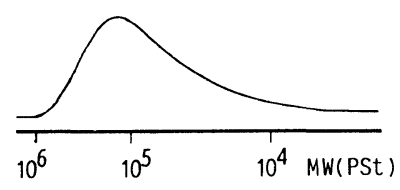

Figure 2. GPC of poly( $p$-TFMS) (Sample: Table 2, run 3).

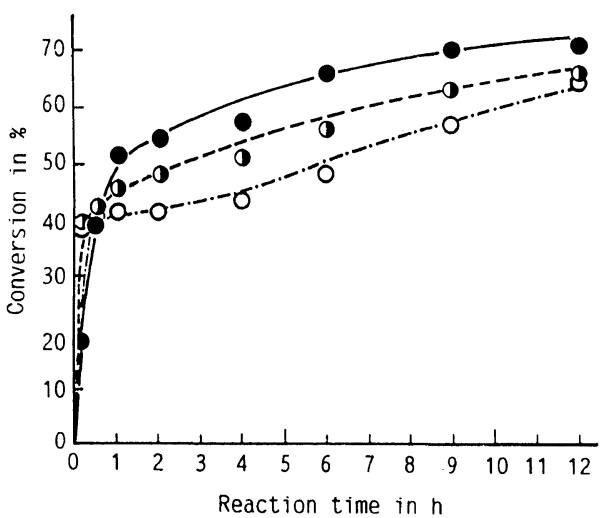

Figure 3. Time vs. conversion curves of the initiation reaction of $\left(\mathrm{C}_{2} \mathrm{H}_{5}\right)_{2}$ AlECA with ortho- $(\mathrm{O})$, meta- $(\mathrm{O})$, and para-TFMS (O) calculated from the ethyl cyanoacetate moiety.

polymer produced was too high.

Initiation reactions of these three monomers with $\mathrm{Et}_{2} \mathrm{AlECA}$ were examined. The results are summarized in Figure 3, which shows the conversion of the ECA moiety measured by vapor phase chromatography after a portion of the reaction mixture was added to acetic acid. The reaction is fast at the early stage and then slower in the later stage of polymerization. The fast initiation reaction of the polymerization of trifluoromethylstyrenes may take place in an anionic fashion by adding ECA anion to the vinyl group as far as the consumption of the initiator is concerned, as reported previously for the anionic polymerization of 2,2,2trifluoroethyl methacrylate with $\mathrm{Et}_{2} \mathrm{AlECA}{ }^{1}$ The initiation reactions of these three monomers exhibit little difference as shown in Figure 3. In general, the reactivity of ortho-, meta- and para-substituted aromatic compounds is different by steric hindrance in many organic reactions. The reactivity in the anionic polym- erization of these three TFMS isomers is, however, concluded to show virtually little difference as far as the initiation and propagation reactions are concerned. The strong electron-withdrawing inductive effect seems, therefore, to overcome the effect of steric hindrance of trifluoromethyl group.

The results presented in this article show anionic mechanism of the polymerization of trifluoromethylstyrenes as far as the initiation reaction is concerned, and strong electronwithdrawing inductive effect of trifluoromethyl group is remarkably evidenced both in initiation and propagation reactions with the initiators of relatively low activity such as organoaluminum compounds. The reactivity order of three isomers examined here is para-> meta->ortho-TFMS though very small difference is detected as far as the polymer yields and initiator consumptions are concerned.

Acknowledgments. This work was supported in part by a grant from Nissan Science Foundation, to which the authors gratefully acknowledge. They also wish to thank Mr. T. Sakai, Mr. M. Muraoka and Miss I. Okoshi for their experimental assistance.

\section{REFERENCES}

1. T. Narita, T. Hagiwara, H. Hamana, T. Miyasaka, A. Wakayama, and T. Hotta, Makromol. Chem., 188, 273 (1987).

2. L. A. Wall, Ed., "Fluoropolymers," Wiley-Interscience, New York, N.Y., (1972).

3. T. Narita, T. Hagiwara, and H. Hamana, Polym. Prepr. Jpn., 35, 222 (1986).

4. M. Ueda and H. Ito, J. Polym. Sci., Polym. Chem. $E d$., 26, 89 (1988).

5. H. Ito, A. F. Renaldo, and M. Ueda, Macromolecules, 22, 45 (1989).

6. T. Narita, T. Hagiwara, H. Hamana, H. Irie, and H. Sugiyama, Polym. J., 19, 985 (1987).

7. H. Muramatsu, T. Ueda, and K. Ito, Macromolecules, 18, 1634 (1985).

8. C. S. Marvel, C. G. Overberger, R. E. Allen, and J. H. Sounders, J. Am. Chem. Soc., 68, 736 (1946).

9. H. Gilman and F. K. Cartledge, J. Organometal, 


\section{Trifluoromethylstyrene}

Chem., 2, 4478 (1964).

10. Y. Kawakami and T. Tsuruta, Bull. Chem. Soc. Jpn., 44, 247 (1971).

11. T. Narita, T. Hagiwara, H. Hamana, and M. Goto,
Makromol. Chem., 187, 731 (1986).

12. T. Tsuruta, "Progress in Polymer Science, Japan," Vol. 3, S. Okamura and M. Takayanagi, Ed., Kodansha, Tokyo, 1972, p. 1. 